\title{
CARACTERÍSTICAS DIMENSIONAIS E PONDERAIS DAS SEMEADORAS-ADUBADORAS DE PRECISÃO NO
} BRASIL

\author{
Tiago R. Francetto ${ }^{*}$, Ravel F. Dagios ${ }^{2}$, João A. Leindecker ${ }^{2}$, Airton dos S. Alonço ${ }^{1}$, Mauro F. Ferreira ${ }^{3}$ \\ ${ }^{1}$ Departamento de Engenharia Rural, Universidade Federal de Santa Maria, Santa Maria, Brasil. \\ ${ }^{2}$ Departamento de Engenharia, Arquitetura e Ciência Agrárias, Universidade de Santa Cruz do Sul, Santa Cruz do Sul, Brasil. \\ ${ }_{3}^{3}$ Departamento de Engenharia Rural, Universidade Federal de Pelotas, Pelotas, Brasil.
}

*E-mail: tiagofrancetto@gmail.com

\section{RESUMO}

O objetivo do trabalho foi analisar as características dimensionais e ponderais das semeadoras-adubadoras de precisão fabricadas no Brasil. Para isso, foi realizado um levantamento de 20 dos principais atributos das máquinas, a fim de confeccionar um banco de dados organizados em uma planilha eletrônica, utilizando-se o software Microsoft Excel. Os resultados indicaram um total de 18 marcas, que englobam 558 modelos, com variação no número de linhas de 1 a 30, capacidade do depósito de sementes de 19,00 a $1.700,00 \mathrm{~kg}$ e, de fertilizante, de 42,0 a $6.400,00 \mathrm{~kg}$. Além disso, a potência requerida total variou de 13,20 a $250,00 \mathrm{~kW}$, a demanda por unidade de semeadura, entre 4,50 a $25,70 \mathrm{~kW} \operatorname{linha}^{-1}$ e a relação massa/potência requerida, entre 10,90 a $130,50 \mathrm{~kg} \mathrm{~kW}^{-1}$. Os dosadores de sementes empregados são os discos horizontal e pneumático, representando 79,57\% e 20,43\% respectivamente. Já os dosadores de fertilizante são os mecanismos helicoidais, com 94,40\%, disco horizontal giratório, com 2,90\%,rotor acanalado, com $2,20 \%$ e rotor dentado, com 0,50\%. Há uma ampla diversidade de semeadoras-adubadoras que possibilitam atender diversos requerimentos, fato que evidencia a necessidade de uma avaliação criteriosa no momento da seleção e aquisição.

Palavras-chave: Informação técnica. Catálogo técnico. Seleção. Aquisição. Dosadores.

\section{Introdução}

Dentre as máquinas agrícolas utilizadas na agricultura, a semeadora-adubadora é uma das que sofreram maiores alterações, tendo em vista sua grande importância no sistema de produção agrícola, pois a realização da operação de semeadura com qualidade é um fator primordial para o sucesso da produção. Possíveis problemas durante essa etapa só poderão ser percebidos após a emergência da cultura, acarretando perdas significativas de produção [1]. Contudo, pela agricultura ser um setor altamente influenciado por características externas, como o clima, deve-se aliar qualidade com eficiência operacional em virtude de o período de semeadura ser, muitas vezes, reduzido. Portanto, deve-se buscar maximizá-la, já que está envolvida de forma direta no custo final de produção.

Nos preparos conservacionistas, entre eles o sistema semeadura direta (SSD), sua importância aumenta, já que as condições do solo e da cobertura geralmente não são favoráveis a deposições das sementes com relação às verificadas nos preparos com mobilização [2]. Apesar das mudanças positivas nas características físicas do solo [3-4], propiciadas pelo sistema, o cultivo continuado pode levar à consolidação natural, advinda da ausência de preparo, ou a sua compactação superficial, devido ao tráfego de máquinas durante as operações necessárias ao cultivo.
Dessa forma, a semeadura direta só foi difundida e possibilitada através da geração e do aprimoramento de tecnologias que garantiram o desenvolvimento das semeadorasadubadoras hábeis de modo a exercerem sua função para garantir um estabelecimento adequado das culturas com o mínimo de revolvimento do solo [5]. Assim, as semeadoras-adubadoras passaram a assumir um papel fundamental no sistema de produção agrícola, uma vez que esses implementos são responsáveis por promover a abertura dos sulcos, dosagem e distribuição das sementes e adubo no solo, bem como o fechamento dos sulcos. Além disso, [6] é o equipamento mais importante para o sucesso do SSD.

Assim, torna-se necessária uma correta seleção dessas máquinas, uma vez que as suas características dimensionais e ponderais e as suas relações influenciam, de forma direta, no seu desempenho. Consequentemente, um dos fatores que contribuem para o sucesso da semeadura direta é a seleção e utilização correta desses equipamentos, pois seu desempenho é afetado pela presença de resíduos culturais sobre o solo [7] e pelas condições de solo impostas [8-9], sendo que a escolha adequada resulta do ajuste do planejamento da produção da propriedade, obtendo-se a máxima eficiência operacional e a capacidade efetiva de trabalho, reduzindo custos.

Contudo, os usuários de semeadoras-adubadoras de precisão se defrontam com uma série de decisões relacionadas no 
momento da seleção e a aquisição, visando a melhor eficiência desses implementos. Uma das formas de realizar essa escolha é a busca de informações sobre o produto, pois, em uma atividade econômica, a disponibilidade de informações é essencial, já que isso deve possibilitar a comparação entre os modelos, sendo o catálogo técnico um dos principais meios de divulgação [10]. Apesar disso, os dados técnicos referentes às máquinas agrícolas são insuficientes e heterogêneos entre os fabricantes e modelos tanto na forma quantitativa quanto qualitativa em virtude da não obrigatoriedade dos ensaios oficiais no Brasil, ficando a responsabilidade ao fabricante pela apresentação desses dados. Além disso, as semeadoras são providas de diversas características relevantes, de forma que sua avaliação conjunta é complexa e demorada. $\mathrm{O}$ agricultor tem dificuldade para escolher um modelo adequado, em função das suas necessidades e das características específicas de sua propriedade, principalmente, pela heterogeneidade entre os catálogos e, em alguns casos, pela falta de informações claras e objetivas [11]. Do mesmo modo, a diversidade de máquinas disponibilizadas no mercado nacional torna a seleção ainda mais complexa.

Em vista disso, este trabalho teve o objetivo de analisar, quantificar, relacionar, comparar e avaliar as características dimensionais e ponderais das semeadoras-adubadoras de precisão disponíveis no mercado brasileiro em função do número de linhas a fim de subsidiar a seleção do modelo mais adequado às necessidades do agricultor.

\section{Metodologia}

Foi realizada, primeiramente, a identificação dos fabricantes nacionais de semeadoras-adubadoras de precisão. Posteriormente, sucedeu-se ao levantamento das características dimensionais e ponderais desses equipamentos, obtidas em catálogos técnicos, manuais e folhetos disponibilizados pelas empresas e, quando necessário, a busca direta com os fabricantes. Foi confeccionado um banco de informações organizadas em uma planilha eletrônica, utilizando-se o software Microsoft Excel para analisar e quantificar as variáveis separadamente, sendo elas: número de linhas, capacidade do depósito de sementes e fertilizantes $(\mathrm{kg})$, massa total $(\mathrm{kg})$, largura de trabalho e total $(\mathrm{mm})$, espaçamento máximo e mínimo $(\mathrm{mm})$, mecanismos distribuidores de fertilizantes e sementes e potência requerida total $(\mathrm{kW})$. Além disso, determinou-se as relações entre capacidade de fertilizante e de sementes, potência requerida por unidade de semeadura $\left(\mathrm{kW}\right.$. linha $\left.^{-1}\right)$, massa e potência requerida total $\left(\mathrm{kg} \cdot \mathrm{kW}^{-1}\right)$, massa por número de linhas $\left(\mathrm{kg}\right.$ linha $\left.{ }^{-1}\right)$, massa e largura de trabalho $\left(\mathrm{kg} \cdot \mathrm{m}^{-1}\right)$, capacidade do depósito de fertilizante e de sementes pela largura de trabalho. Outrossim, calculou-se a autonomia de fertilizante e sementes e sua relação, assim como a amplitude de espaçamento ( $\mathrm{mm}$ ).

As autonomias de fertilizante e sementes foram estimadas a fim de se obter a quantidade de hectares (ha) possíveis de serem realizados pela semeadora sem reabastecimento para a cultura da soja. A primeira foi obtida com base para o cálculo de $350 \mathrm{~kg}$ de fertilizante por ha, enquanto que, na segunda, empregou-se a distribuição de $65 \mathrm{~kg}$ de sementes por ha. Desse modo, obtêm-se uma relação entre essas variáveis de $5,38 \mathrm{~kg}$ de fertilizante para cada quilo de sementes. Destaca-se que a utilização desses valores é simplesmente para efeito de cálculo e para possibilitar a comparação entre as variáveis. Ademais, avaliou-se a relação entre capacidades dos depósitos pela largura de trabalho com base no coeficiente tecnológico de semeadoras [12]. Considera-se adequada a capacidade de armazenamento de fertilizantes quando esta apresentar valor igual ou superior a $275 \mathrm{~kg}$ para cada metro de largura de trabalho, enquanto que, para sementes, esse valor deve ser de $100 \mathrm{~kg}$ para cada metro de largura de trabalho.

Todas as características foram estratificadas em função do número de linhas dos equipamentos, nas faixas inferiores a 10 , 10 a 20 e 20 a 30 linhas de semeadura, a fim de se verificar possíveis relações e comparações.

\section{Resultados e discussões}

Foram avaliadas as informações oriundas de 18 marcas, que englobaram um total de 558 modelos, distribuídos por estrato, conforme verificado na Tabela 1.

Tabela 1 - Número de semeadoras por estrato

\begin{tabular}{cccc}
\hline Estratos & 1 a 10 linhas & 11 a 20 linhas & 21 a 30 \\
\hline Número & 315 & 231 & 12 \\
\hline
\end{tabular}

Observa-se que o maior número de semeadoras disponíveis no mercado nacional é composto de 1 a 10 linhas, com 315 modelos, representando $56,45 \%$ do total. Além disso, as equipadas com 11 a 20 linhas correspondem a 41,39\%, com um número de 231 modelos disponíveis e as com 21 a 30 linhas, apenas $2,15 \%$, com 12 semeadoras.

A capacidade total e por linha dos depósitos de fertilizantes são apresentadas na Tabela 2 e na Tabela 3.

Tabela 2 - Capacidade total dos depósitos de adubo (kg)

\begin{tabular}{cccc}
\hline Estratos & 1 a 10 linhas & 11 a 20 linhas & 21 a 30 \\
\hline Máximo & $2.800,00$ & $4.200,00$ & $6.400,00$ \\
Mínimo & 42,00 & $2.419,73$ & $4.571,33$ \\
Média & 778,36 & $1.090,00$ & $3.900,00$ \\
\hline
\end{tabular}

Ocorreu um incremento dos valores máximo, mínimo e média da capacidade de fertilizante com o aumento do número de linhas. Entretanto, foi constatada uma proximidade entre a capacidade máxima das semeadoras-adubadoras de 11 a 20 linhas, com a carga mínima do estrato constituído de 21 a 30 linhas. Do mesmo modo, semeadoras de 1 a 10 linhas apresentaram uma diferença de $2.758,0 \mathrm{~kg}$ entre o valor máximo 
e o mínimo. Na classe de 11 a 20, essa diferença foi de 3.110,0 $\mathrm{kg}$ e, para a classe de 21 a 30 linhas, foi de $2.500,0 \mathrm{~kg}$.

Tabela 3 - Capacidade por linha dos depósitos de fertilizantes $\left(\mathrm{kg} \mathrm{linhas}^{-1}\right)$

\begin{tabular}{cccc}
\hline Estratos & 1 a 10 linhas & 11 a 20 linhas & 21 a 30 \\
\hline Máximo & 280,75 & 247,31 & 233,33 \\
Mínimo & 29,75 & 97,92 & 162,50 \\
Média & 110,23 & 171,25 & 195,11 \\
\hline
\end{tabular}

Os valores médios da capacidade dos reservatórios de fertilizantes por linha tendem a aumentar com o incremento do número de linhas. Além disso, verificou-se que as alterações entre os índices máximos e mínimos diminuíram em função do aumento das linhas, na qual, para a primeira classe, evidenciou-se uma variação de $89,40 \%$, para a segunda, de $60,41 \%$ e, para a terceira, de $30,36 \%$. Por outro lado, os valores máximos apresentaram-se contrários a essa tendência, ou seja, eles diminuíram com o acréscimo do número de linhas.

A capacidade total e por linha dos depósitos de sementes está disposta na Tabela 4 e na Tabela 5.

Tabela 4 - Capacidades total dos depósitos de sementes $(\mathrm{kg})$

\begin{tabular}{cccc}
\hline Estratos & 1 a 10 linhas & 11 a 20 linhas & 21 a 30 \\
\hline Máximo & 839,00 & 1270,00 & 1700,00 \\
Mínimo & 19,00 & 180,00 & 840,00 \\
Média & 260,63 & 648,32 & 1129,17 \\
\hline
\end{tabular}

Tabela 5 - Capacidades por unidade de semeadura dos depósitos de sementes (kg $\underline{\left.\text { linha }^{-1}\right)}$

\begin{tabular}{cccc}
\hline Estratos & 1 a 10 linhas & 11 a 20 linhas & 21 a 30 \\
\hline Máximo & 86,33 & 92,00 & 77,27 \\
Mínimo & 12,50 & 10,59 & 40,00 \\
Média & 38,18 & 46,04 & 47,91 \\
\hline
\end{tabular}

Observou-se que, com o aumento do número de linhas, ocorre um incremento dos valores máximo, mínimo e a média da capacidade de sementes. Todavia, ressalta-se que, especificadamente, o valor mínimo das semeadoras-adubadoras de 21 a 30 linhas é semelhante ao valor máximo das máquinas com 1 a 10 linhas. Outrossim, evidenciou-se uma variação significativa entre os valores máximos e mínimos, sendo de $820,0 \mathrm{~kg}$ para a classe de $1 \mathrm{a} 10$ linhas, $1.090,0 \mathrm{~kg}$ para a classe de 11 a 20 e $860,0 \mathrm{~kg}$ para a classe de 21 a 30 linhas. Tal fato demonstra a ocorrência de capacidades operacionais distintas entre estratos e entre modelos da mesma classe.

Ademais, um incremento do valor médio da capacidade do reservatório de sementes com o aumento do número de linha foi observado, fato teoricamente esperado e, possivelmente, um dos requisitos para um bom rendimento operacional. Entretanto, ressalta-se que, em uma mesma classe, ocorreram variações entre valores máximos e mínimos, de 85,52\% para semeadoras de 1 a
10 linhas, $88,49 \%$ de 11 a 20 linhas e $48,23 \%$ para as de 21 a 30 linhas. Portanto, evidencia-se que as máquinas com menor número de linhas (inferior a 20) apresentam maiores alterações nas capacidades dos reservatórios quando comparados diferentes modelos.

Nesse cenário, pode-se observar a ocorrência de uma variação significativa entre as capacidades dos depósitos de sementes e fertilizantes mínima e máxima das semeadorasadubadoras dentro da mesma classe do número de linhas. Em alguns casos, semeadoras-adubadoras de classes menores podem vir a apresentar uma capacidade operacional superior à de classes maiores, quando avaliado somente esse parâmetro, em virtude de seus reservatórios possuírem uma maior capacidade. Além disso, deve-se dar atenção à relação entre essas capacidades, característica esta apresentada na Tabela 6 .

Tabela 6 - Relação entre capacidade de depósitos de fertilizante e sementes

\begin{tabular}{cccc}
\hline Estratos & 1 a 10 linhas & 11 a 20 linhas & 21 a 30 \\
\hline Máximo & 9,49 & 16,11 & 4,76 \\
Mínimo & 1,00 & 1,46 & 2,82 \\
Média & 2,9 & 3,86 & 4,21 \\
\hline
\end{tabular}

Verificou-se um incremento da relação com o aumento do número de linhas quando observados os valores mínimos e a média. No entanto, observa-se a existência de baixas razões em todos os extratos com maior significância em semeadoras de 11 a 20 linhas, com variação entre os valores máximos e mínimos de $90,94 \%$ e, em máquinas equipadas com 1 a 10 linhas com $89,46 \%$, enquanto que, no maior extrato, essa alteração foi de apenas $40,76 \%$. Dessa forma, como as capacidades dos depósitos são itens influenciadores da autonomia dos insumos sementes e fertilizante, deve-se almejar alcançar uma adequada relação para que ambas sejam esgotadas na mesma proporção, em virtude de que, desde que bem dimensionados, podem diminuir o custo de produção devido à redução do número de paradas para abastecimentos. A Figura 1 ilustra os resultados da avaliação dos depósitos de sementes, e a Figura 2, dos depósitos de fertilizante, em função da largura de trabalho.

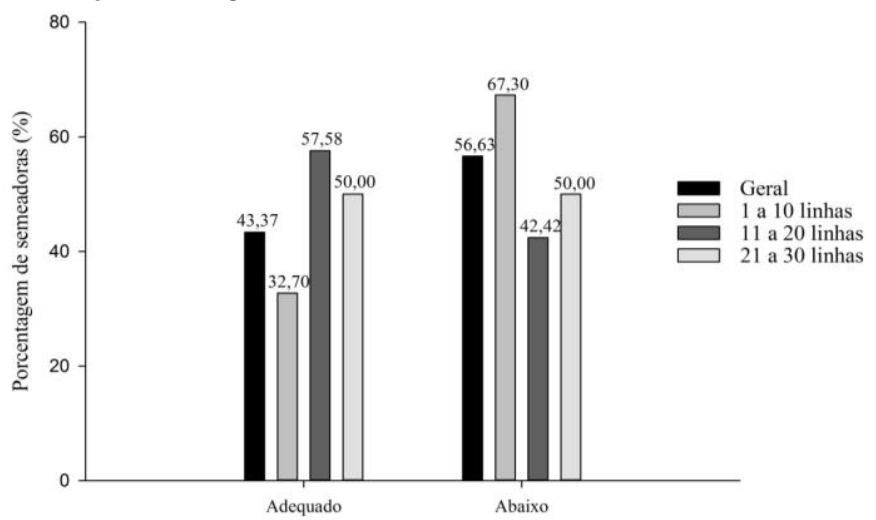

Figura 1 - Avaliação das capacidades dos depósitos de sementes 
A análise das capacidades dos depósitos de sementes através da utilização do coeficiente tecnológico demonstrou que apenas $43,37 \%$ das semeadoras fabricadas no Brasil apresentam essa variável adequada. $\mathrm{O}$ estrato de 1 a 10 linhas apresentou a menor porcentagem de semeadoras apropriadas, com 103 semeadoras, que representam $32,70 \%$. Já a classe intermediária foi a que apresentou o maior índice de máquinas adequadas, com $57,58 \%$, enquanto que, no terceiro estrato, esse valor foi de $50,00 \%$.

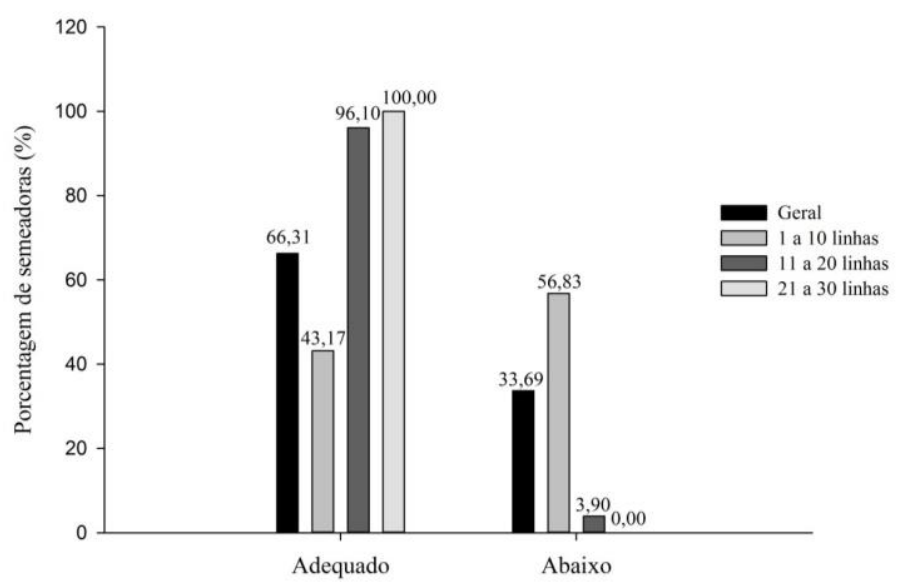

Figura 2 - Avaliação das capacidades dos depósitos de fertilizante

A avaliação dos depósitos de fertilizante apresentou $66,31 \%$ de semeadoras adequadas, com $22,94 \%$ a mais do que na análise dos depósitos de sementes. Outrossim, semeadoras com até 10 linhas foram as que apresentaram o menor valor de depósitos apropriados, com 43,17\%. Ademais, 96,10\% das máquinas de 11a 20 linhas apresentam seus depósitos adequados e, quando analisadas semeadoras de 21 a 30 linhas, esse valor foi de $100,00 \%$.

A variação da autonomia de sementes em função dos estratos de número de linhas é apresentada na Tabela 7.

Tabela 7 - Autonomia de sementes $\left(\mathrm{kg} \mathrm{kg}^{-1}\right)$

\begin{tabular}{cccc}
\hline Estratos & 1 a 10 linhas & 11 a 20 linhas & 21 a 30 \\
\hline Máximo & 12,91 & 19,54 & 26,15 \\
Mínimo & 0,29 & 5,08 & 12,92 \\
Média & 4,04 & 10,02 & 17,37 \\
\hline
\end{tabular}

Observou-se incremento da autonomia de sementes em função do aumento do número de linhas quando analisados os valores máximos, mínimos e a média geral da variável. Contudo, verifica-se uma grande variação entre o valor máximo e mínimo das semeadoras, o que indica a ocorrência de capacidades distintas entre modelos da mesma classe. Semeadorasadubadoras de 1 a 10 linhas apresentaram alteração de 97,75\%, seguida pelas máquinas de 11 a 20 linhas, com $74,00 \%$ e as de 21 a 30 linhas, com 50,59\%. Além disso, verificou-se maior diferença técnica entre as semeadoras de 1 a 10 e as 11 a 20 linhas, com $148,02 \%$ de variação quando comparado o valor médio. Já quando analisada esta última com semeadoras de 21 a 30 linhas, a diferença foi de apenas $73,35 \%$. Dessa forma, máquinas menores apresentam maiores variações nessa variável do que semeadoras de maior porte.

A autonomia de fertilizantes das semeadoras-adubadoras é apresentada na Tabela 8.

Tabela 8 - Autonomia de fertilizante $\left(\mathrm{kg} \mathrm{kg}^{-1}\right)$

\begin{tabular}{cccc}
\hline Estratos & 1 a 10 linhas & 11 a 20 linhas & 21 a 30 \\
\hline Máximo & 10,89 & 12,00 & 18,29 \\
Mínimo & 0,12 & 3,11 & 11,14 \\
Média & 2,26 & 6,91 & 13,06 \\
\hline
\end{tabular}

Notou-se um aumento da autonomia de fertilizante em função do número de linhas das semeadoras-adubadoras. Esse acréscimo foi de $205,75 \%$ entre máquinas de 1 a 10 e 11 a 20 linhas e de 89,00 entre estas últimas e as de 21 a 30 linhas. Ademais, verificou-se que as semeadoras menores apresentaram a maior alteração na autonomia de fertilizante, com 98,90\%, seguidas pelas de 11 a 20 linhas, com 74,08\%, e as de 21 a 30 linhas, com $39,09 \%$.

Os valores da relação entre a autonomia de fertilizante e de sementes em função do estrato de número de linhas são apresentados na Tabela 9 .

Tabela 9 - Relação entre autonomia de fertilizante e sementes $\left(\mathrm{kg} \mathrm{kg}^{-1}\right)$

\begin{tabular}{cccc}
\hline Estratos & 1 a 10 linhas & 11 a 20 linhas & 21 a 30 \\
\hline Máximo & 1,12 & 1,07 & 0,88 \\
Mínimo & 0,19 & 0,27 & 0,52 \\
Média & 0,54 & 0,71 & 0,78 \\
\hline
\end{tabular}

A relação entre a autonomia de fertilizante e sementes apresentou redução, o que é justificado em função do acréscimo destas quando incrementado o número de linhas. Semeadoras da primeira classe apresentaram a maior variação entre o valor máximo e mínimo, com de $83,04 \%$, seguidas pelas de 11 a 20 linhas, com 74, 77\%. Já as de 21 a 30 linhas apresentaram a menor alteração, com 40,91\%.

Além disso, verificou-se que semeadoras-adubadoras com menor número de linhas apresentaram o menor valor médio, com $0,54 \mathrm{~kg} \mathrm{~kg}^{-1}$, seguidas pelas de 11 a 20 linhas e as com $21 \mathrm{e}$ 30 , linhas com 0,71 e $0,78 \mathrm{~kg} \mathrm{~kg}^{-1}$, respectivamente.

Os valores referentes à massa total e por linha são mostrados na Tabela 10 e Tabela 11. 
Tabela 10 - Massa total $(\mathrm{kg})$

\begin{tabular}{cccc}
\hline Estratos & 1 a 10 linhas & 11 a 20 linhas & 21 a 30 \\
\hline Máximo & $7.812,00$ & $16.470,00$ & $22.050,00$ \\
Mínimo & 196,00 & $1.950,00$ & $11.880,00$ \\
Média & $3.387,78$ & $9.486,58$ & $16.163,00$ \\
\hline
\end{tabular}

Tabela 11 - Massa por linha $\left(\mathrm{kg} \operatorname{linha}^{-1}\right)$

\begin{tabular}{cccc}
\hline Estratos & 1 a 10 linhas & 11 a 20 linhas & 21 a 30 \\
\hline Máximo & 938,00 & 934,55 & 890,91 \\
Mínimo & 172,00 & 71,04 & 542,50 \\
Média & 484,81 & 668,83 & 689,55 \\
\hline
\end{tabular}

Observou-se que semeadoras com 1 a 10 linhas, quando analisado o valor médio dessa variável, apresentaram 180,02\% e $377,10 \%$ a menos de massa do que as equipadas com 11 a 20 e 21 a 30 respectivamente. Além disso, as providas com 11 a 20 possuem $70,37 \%$ a menos do que as de maior porte. Tais variações devem-se, dentre outras variáveis, pelas diferentes características de projeto (tipos de mecanismos empregados e da construção do chassi) e da largura de trabalho e largura total, estas últimas exibidas na Tabela 12 e Tabela 13. Entretanto, quando observados os valores máximos e mínimos, não se verificou essa tendência de aumento em função do número de linhas, demonstrando a necessidade de uma avaliação mais criteriosa desse item, já que influencia a força de tração requerida pela semeadora [13].

Tabela 12 - Largura de trabalho (m)

\begin{tabular}{cccc}
\hline Estratos & 1 a 10 linhas & 11 a 20 linhas & 21 a 30 \\
\hline Máximo & 4,95 & 9,50 & 13,32 \\
Mínimo & 0,90 & 2,74 & 8,55 \\
Média & 2,86 & 6,04 & 10,47 \\
\hline
\end{tabular}

Tabela 13 - Largura total (m)

\begin{tabular}{cccc}
\hline Estratos & 1 a 10 linhas & 11 a 20 linhas & 21 a 30 \\
\hline Máximo & 5,91 & 9,94 & 14,80 \\
Mínimo & 0,90 & 4,08 & 9,25 \\
Média & 3,62 & 6,85 & 11,20 \\
\hline
\end{tabular}

A Tabela 14, a Tabela 15 e a Tabela 16 expõem os valores dos espaçamentos máximo, mínimo e a amplitude entre ambas variáveis, respectivamente.

Tabela 14 - Espaçamento máximo (m)

\begin{tabular}{cccc}
\hline Estratos & 1 a 10 linhas & 11 a 20 linhas & 21 a 30 \\
\hline Máximo & 1,60 & 1,00 & 0,90 \\
Mínimo & 0,40 & 0,38 & 0,38 \\
Média & 0,81 & 0,78 & 0,68 \\
\hline
\end{tabular}

Tabela 15 - Espaçamento mínimo (m)

\begin{tabular}{cccc}
\hline Estratos & 1 a 10 linhas & 11 a 20 linhas & 21 a 30 \\
\hline Máximo & 0,90 & 0,80 & 0,45 \\
Mínimo & 0,16 & 0,17 & 0,38 \\
Média & 0,43 & 0,45 & 0,41 \\
\hline
\end{tabular}

Tabela 16 - Amplitude de espaçamentos (m)

\begin{tabular}{cccc}
\hline Estratos & 1 a 10 linhas & 11 a 20 linhas & 21 a 30 \\
\hline Máximo & 1,43 & 0,73 & 0,50 \\
Mínimo & 0,00 & 0,00 & 0,00 \\
Média & 0,38 & 0,33 & 0,28 \\
\hline
\end{tabular}

Em todos os estratos, encontraram-se semeadoras que não possibilitam a variação do espaçamento entre linhas. Além disso, as semeadoras constituídas com até 10 linhas foram as que apresentaram o maior espaçamento máximo e a maior amplitude. Ademais, o valor médio da amplitude manteve-se próximo em todos os estratos, com uma variação máxima de $0,10 \mathrm{~m}$.

Encontraram-se, ainda, 4 mecanismos dosadores de fertilizantes empregados nas semeadoras, sendo eles a rosca sem fim (RF), o disco horizontal (DH), o rotor dentado (RD) e o cilindro acanalado (CA), expostos, por extrato, na Tabela 17.

Tabela 17 - Mecanismos dosadores de fertilizantes

\begin{tabular}{ccccc}
\hline \multicolumn{5}{c}{ Número de semeadoras } \\
\hline Estratos & RF & DH & RD & CA \\
\hline 1 a 10 & 284 & 16 & 3 & 12 \\
11 a 20 & 231 & 0 & 0 & 0 \\
21 a 30 & 12 & 0 & 0 & 0 \\
\hline
\end{tabular}

Evidencia-se que o mecanismo dosador de fertilizante utilizado em semeadoras com maior representatividade é o helicoidal, encontrado em 527 modelos, representando 94,44\% do total. Destes, $53,89 \%$ estão presentes em semeadoras equipadas com 1 a 10 linhas, $43,83 \%$ nas de 11 a 20 linhas e $2,27 \%$ nas de 21 a 30 linhas. Além disso, o primeiro extrato foi o único que apresentou outros mecanismos de dosagem, como o disco horizontal giratório, o cilindro acanalado e o rotor dentado, representando $2,86 \%, 2,15 \%$ e $0,53 \%$ respectivamente.

Em 2003, o dosador helicoidal representava $65,10 \%$ dos mecanismos dosadores utilizados em semeadoras do país [14]. Já em 2011, sua participação passou para 89,38\% [15]. O aumento da utilização dos dosadores de eixo helicoidal provavelmente se deu devido à eficiência e praticidade desse mecanismo.

Na Tabela 18, são apresentados os tipos de dosadores de sementes, por estrato de número de linhas, utilizados nas semeadoras. 
Tabela 18 - Mecanismos dosadores de sementes por estrato

\begin{tabular}{ccc}
\hline \multicolumn{3}{c}{ Número de semeadoras } \\
\hline Estratos & Disco horizontal & Disco pneumático \\
\hline 1 a 10 & 281 & 34 \\
11 a 20 & 157 & 74 \\
21 a 30 & 6 & 6 \\
\hline
\end{tabular}

Observa-se que as semeadoras-adubadoras nacionais utilizam apenas dois sistemas de dosagem para semente, o disco horizontal e o disco pneumático. Ambos dosadores são empregados nas três classes de números de linhas, de forma que o disco horizontal é o mais utilizado, representando $79,57 \%$ das máquinas. Esse mecanismo está presente em 50,36\% das semeadoras equipadas com 1 a 10 linhas, 28,14\% com 11 a 20 linhas e 1,07\% com 21 a 30 linhas. Além disso, o dosador disco pneumático encontra-se aplicado em $20,43 \%$ das semeadoras. Este se encontra distribuído em 6,10\% de 1 a 10 linhas, 13,26\% de 11 a 20 linhas e $1,07 \%$ de 21 a 30 linhas.

A potência requerida total, indicada pelos fabricantes, é apresentada na Tabela 19, enquanto que a potência requerida por unidade de semeadura é apresentada na Tabela 20.

Tabela 19 - Potência requerida total $(\mathrm{kW})$

\begin{tabular}{cccc}
\hline Estratos & 1 a 10 linhas & 11 a 20 linhas & 21 a 30 \\
\hline Máximo & 123,04 & 250,04 & 235,36 \\
Mínimo & 13,24 & 54,58 & 170,00 \\
Média & 62,89 & 129,60 & 191,18 \\
\hline
\end{tabular}

Tabela 20 - Potência requerida por linha $\left(\mathrm{kW}\right.$. linha $\left.^{-1}\right)$

\begin{tabular}{cccc}
\hline Estratos & 1 a 10 linhas & 11 a 20 linhas & 21 a 30 \\
\hline Máximo & 25,74 & 14,71 & 8,83 \\
Mínimo & 6,29 & 4,55 & 7,36 \\
Média & 10,19 & 9,19 & 8,21 \\
\hline
\end{tabular}

Observou-se a ocorrência de um incremento no requerimento de potência quando avaliado o valor médio total das semeadoras. Por outro lado, quando analisado o valor médio por linha, evidencia-se uma redução dessa variável. A primeira condição é devido, principalmente, ao acréscimo de massa e do maior número de elementos que estão em interação com o solo. Já a segunda, deve-se, possivelmente, a uma melhor adequação no projeto, alcançando uma distribuição adequada da massa total da máquina e utilização de elementos, como os de corte de palha e abertura de sulco, com características geométricas que requerem menos potência, já que estes proporcionam distintos requerimentos em função da interação com os demais elementos da máquina [16].

Na Tabela 21, está disposta a relação entre massa total e a potência requerida.
Tabela 21 - Relação entre massa total e potência requerida $\left(\mathrm{kg} \mathrm{kW}^{-1}\right)$

\begin{tabular}{cccc}
\hline Estratos & 1 a 10 linhas & 11 a 20 linhas & 21 a 30 \\
\hline Máximo & 100,45 & 130,52 & 111,91 \\
Mínimo & 12,76 & 10,90 & 66,43 \\
Média & 50,46 & 73,98 & 84,22 \\
\hline
\end{tabular}

A relação entre massa total e potência requerida apresentou um aumento de $66,90 \%$ entre o estrato menor e o maior e de $13,84 \%$ entre o intermediário e o maior. Já quando analisado entre as semeadoras de 1 a 10 linhas e 11 a 20 linhas, esse acréscimo foi de $46,61 \%$. Contudo, estas últimas apresentaram a maior diferença entre semeadoras do mesmo estrato, com 91,65\%, seguidas pelas constituídas por até 10 linhas, com 87,30\%, e as de 21 a 30 linhas, com 40,64\%.

\section{Conclusões}

Conclui-se que há uma ampla diversidade de semeadoras-adubadoras, assim como características dimensionais e ponderais e suas relações no Brasil, as quais possibilitam atender diversos tipos de produtores.

Pela diversidade de características técnicas, existe a necessidade de uma avaliação criteriosa no momento da seleção e aquisição dessas máquinas, principalmente de semeadoras menores, pois as particularidades de cada uma deverão suprir as necessidades que a semeadora irá desempenhar.

Semeadoras de porte menor, com mesmo número de linhas, apresentam as maiores diferenças técnicas que afetam a capacidade operacional, com maior significância para as máquinas compostas por $8,7,6$ e 5 linhas respectivamente. Já máquinas com maior número de linhas, em comparação às de menor, apresentam menores diferenças técnicas.

\section{DIMENSIONAL AND PONDERAL CHARACTERISTICS OF ROW CROP PLANTERS IN BRAZIL}

ABSTRACT: This study aimed to analyze the dimensional and ponderal characteristics of row crop planters made in Brazil. Therefore, a survey of its 20 major attributes was conducted in order to build a database organized in a spreadsheet by using Microsoft Excel software. The results indicated a total of 18 brands, encompassing 558 models, varying in the number of lines from 1 to 30 , the capacity of the seed deposits from 19.00 to $1.700 \mathrm{~kg}$ and fertilizer from 42.00 to $6.400 \mathrm{~kg}$. Furthermore, the total power required ranged from 13.20 to $250.00 \mathrm{~kW}$, the need per sowing unit varied between 4.50 to $25.70 \mathrm{~kW} \operatorname{line}^{-1}$ and the relation mass/power required ranged from 10.90 to $130.50 \mathrm{~kg}$ $\mathrm{kW}^{-1}$. The seed meters used are the horizontal and pneumatic disc, representing $79.57 \%$ and $20.43 \%$ respectively. The fertilizer meters are the helical mechanisms, with $94.40 \%$, horizontal rotating disc, with $2.90 \%$, ridged traction wheel, with $2.20 \%$ and 
toothed rotor, with $0.50 \%$. There is a wide diversity of row crop planters enabling to meet various requirements, what stresses the need for a careful evaluation when choosing and purchasing one.

Keywords: Technical information. Technical catalog. Selection. Purchase. Metering mechanics.

\section{Referências}

[1] MODOLO, A. J.; TROGELlO, E.; NUNES, A. L.; FERNANDES, H. C.; SILVEIRA, J. C. M. DA; DAMBRÓS, M. P. Efeito de cargas aplicadas e profundidades de semeadura no desenvolvimento da cultura do feijão em sistema plantio direto. Ciência e Agrotecnologia, v. 34, n. 3, p. 739-745, 2010.

[2] BONINI, A. K.; GABRIEL FILHO, A.; SECCO, D.; SOUZA, R. F. DE; TAVARES, C. Atributos físicos e requerimento de potencia de uma semeadoraadubadora em um latossolo sob estados de compactação. Engenharia Agrícola, v. 28 , n. 1 , p. $136-144,2008$

[3] ROSA, D. P. DA; REICHERT, J. M.; SATTLER, A.; REINERT, D. J.; MENTGES, M. I.; VIEIRA, D. A. Relação entre solo e haste sulcadora de semeadora em Latossolo escarificado em diferentes épocas. Pesquisa agropecuária brasileira, v. 43, n. 3, 2008.

[4] BLAINSKI, É.; TORMENA, C. A.; GUIMARÃES, R. M. L.; NANNI, M. R. Qualidade física de um latossolo sob plantio direto influenciada pela cobertura do solo. Revista Brasileira de Ciência do Solo, v. 36, n. 1, p. 79-87, 2012.

[5] FRANCETTO, T. R; et al. Utilização do índice de adequação de semeadorasadubadoras de precisão como ferramenta de comparação entre modelos. In: CONGRESSO BRASILEIRO DE ENGENHARIA AGRÍCOLA, 42., 2013. Fortaleza. Anais... Fortaleza: Sociedade Brasileira de Engenharia Agrícola, 2013.

[6] SANTOS, A. P.; TOURINO, M. C. C.; VOLPATO, C. E. S. Qualidade de semeadura na implantação da cultura do milho por três semeadoras-adubadoras de plantio direto. Ciência e Agrotecnologia, v. 32, n. 5, p. 1601-1608, 2008.

[7] CEPIK, C. T. C.; TREIN, C. R.; LEVIEN, R. Força de tração e mobilização do solo por hastes sulcadoras de semeadora-adubadora. Revista Brasileira de Engenharia Agrícola e Ambiental, v. 14, n. 5, p. 561-566, 2010.

[8] KARAYEL, D.; SARAUSKIS, E. Effect of downforce on the performance of no-till disc furrow openers for clay-loam and loamy soils. Agricultural Engineering Research papers, v. 43, n. 3, p. 16-24, 2011

[9] LEVIEN, R.; FURLANI, C. E. A.; GAMERO, C. A.; CONTE, O.; CAVICHIOLI, F. A. Semeadura direta de milho com dois tipos de sulcadores de adubo, em nível e no sentido do declive do terreno. Ciência Rural, v. 41, n. 6, p. 1003-1010, 2011

[10] MIALHE, L. G. Máquinas Agrícolas: ensaios \& certificação. Piracicaba: FEALQ, 1996. $722 \mathrm{p}$

[11] SILVA, M. R. DA.; DANIEL, L. A.; PECHE FILHO, A. Uso da teoria de números índices para adequação de semeadoras-adubadoras de precisão. Revista Brasileira de Engenharia Agrícola e Ambiental, v. 11, n. 2, p. 222-229, 2007.

[12] FERREIRA, M. F.; NEUJAHR, E. B.; DALLMEYER, A. U.; SCHNEIDER, V. Coeficiente tecnológico de semeadoras para semeadura direta: Descrição dos parâmetros analisados e guia de utilização. Santa Maria: Universidade Federal de Santa Maria, 1998, $61 \mathrm{p}$

[13] MERCANTE, E.; SILVA, S. DE L.; MODOLO, A. J.; SILVEIRA, J. C. M da. Demanda energética e distribuição de sementes de milho em função da velocidade de duas semeadoras. Revista Brasileira de Engenharia Agrícola e Ambiental, v. 9, n. 3, p. 424-428, 2005.

[14] SILVA, M. R. da. Classificação de semeadoras-adubadoras de precisão para o sistema plantio direto conforme o índice de adequação. Dissertação (Mestrado em Engenharia Agrícola) Universidade Estadual de Campinas, Campinas, 2003.

[15] LEINDECKER, J. A.; DAGIOS, R. F.; PRADE, R.; FRANCETTO, T. R.; FRANTZ, U. G. Nível tecnológico dos mecanismos dosadores de fertilizante empregados nas semeadoras adubadoras em linhas de precisão. In: Seminário de iniciação científica, 17. Santa Cruz do Sul, RS: Universidade de Santa Cruz do Sul, 2011

[16] FRANCETTO, T. R. Desempenho de mecanismos de corte dos resíduos culturais e abertura de sulco para a semeadura direta. Dissertação (Mestrado em Engenharia Agrícola) Universidade Federal de Santa Maria, Santa Maria, 2014 